\title{
OENOTHERA-PROEVEN IN 1919
}

door J. P. Lotsy.

(met 5 foto's)

lk moet beginnen met aan Dr. ReNNER te München mijne excuses aan te bieden voor een onvolledig citaat in mijn vorig Oenotheraartikel, waardoor ik hem iets anders heb laten zeggen dan hij werkelijk gezegd heeft. Ik kom hierop straks, bij het bespreken der synthetische Lamarckiana's, terug doch wilde het reeds op deze, in het oogvallende plaats, vermelden.

\section{OPVALLEND KRACHTIGE VORMEN.}

In de cultures waarover in Genetica I Afl. 1 bericht werd, traden de volgende opvallend krachtige vormen op.

Proefnummer 2. O. biennilaeta zelfbevrucht. No. 2 A14 en No. 2 D6 dus 2 van de 190 individuen, die deze cultuur telde.

"

4. $O$. murilaeta zelfbevrucht 9 exemplaren, dus 9 van de 180 individuen, die deze cultuur telde.

" 34A. O. biennis $9 \times$ murilaeta $\delta 2$ exemplaren, dus 2 van de 91 individuen, die deze cultuur telde.

In dat artikel werden deze vormen als gigas-vormen aangeduid, evenwel slechts voorloopig, zooals blijkt uit het gezegde op p. 21 van dat artikel: „, bovendien echter 2 zeer breedbladige en forsche planten, die misschien het beste als biennilaeta-gigas kunnen worden aangeduid. Indien deze benaming juist is, zal moeten blijken dat zij tetraploid zijn."

Individueel werd van deze planten het volgende gezegd:

$O$. biennilaeta gigas ex proef 2

"Van den aldus aangeduiden vorm traden 2 planten op: $2 \mathrm{~A} 14$ en 2D6. Deze verschillen op zoodanige wijze, dat men zou vermoeden dat indien $2 \mathrm{~A} 14$ werkelijk mocht blijken tetra- 
ploid te zijn, 2D6 triploid - dus een zoogenaamde Hero-vorm - zal zijn."

O. murilaeta gigas ex proef 4

„Deze trad ten getale van 9 op; zijn het inderdaad gigasplanten, dan zijn zij wel tetraploid, uiterlijk althans zijn geen Hero's voorhanden."

O. biennilaeta-gigas ex proef $34 \mathrm{~A}$

„Bovendien werden nog twee gigas-achtige biennilaeta's aangetroffen, die wellicht triploid zijn."

Voor wij de verdere proeven met een deel dezer planten beschrijven, dient nagegaan te worden wat in de literatuur over gigas. vormen bekend is.

In zijne Mutationstheorie Bd I p. 159 vermeldt DE VRIEs, dat eene gigas-vorm in 1895 in zijne Lamarckiana-familie (Mutationstheorie I p. 157) in één exemplaar ontstond. Deze $O$. Lamarckianagigas, duidt DE VRIEs als $O$. gigas aan, zij bleek bij uitzaaiing constant te zijn, want van de 450 door zelfbevruchting verkregen exemplaren week slechts één af, dat dwerggroei vertoonde en door DE VRIES $O$. gigas nanella werd genoemd.

Wij komen hier al dadelijk voor een principieele nomenclatuurquestie te staan. In een noot op p. 158 zijner Mutations-Theorie Bd I zegt de Vries:

"In Bezug auf die Nomenclatur sei hier vorläufig bemerkt, dass meine Pflanzen gleich bei ihrer Geburt mit einer stattlichen Reihe von synonymen Namen beleğt werden müssen. Einige Autoren rechnen die $O$. Lamarckiana als Varietät zu O. biennis. Andere trennen die Untergattung Onagra als Gattung ab. Es entstehen dadurch z. B. für $O$. gigas die folgenden gleichberechtigten Namen:

Oenothera gigas

Oenothera Lamarckiana gigas

Oenothera biennis gigas

Oenothera biennis Lamarckiana gigas

Onagra gigas

Onagra Lamarckiana gigas

Onagra biennis gigas

Oenothera biennis Lamarckiana gigas ${ }^{1}$ ) enz.

1) Mutationstheorie Bd I p. $23 ̧ 1$. 
Dat is van bloot nomenclatuurstandpunt natuurlijk juist, maar van genetisch standpunt bezien, maakt het een geweldig onderscheid of men de opvallend krachtige vorm, die uit O. Lamarckiana ontstond als $O$. Lamarckiana gigas of als $O$. gigas aanduidt. In het eerste geval toch wekken wij geen anderen indruk dan dat wij een opvallend grooten vorm van $O$. Lamarckiana hebben aangetroffen zooals b.v. een reus onder de menschen - in het andere geval dien dat een geheel nieuwe soort uit $O$. Lamarckiana is ontstaan.

Gebruikt men de verschillende nomenclaturen dooréén, dan krijgt men inconsequentie's zooals wij er boven reeds een zagen: een afwijkende vorm (in casu een gigas-vorm) uit O. Lamarckiana ontstaan duidt DE VRIES als $O$. gigas, een afwijkende vorm (in casu een nanella-vorm) uit $O$. gigas ontstaan niet als $O$. nanella, maar als $O$. gigas nanella aan.

Behalve deze in 1895 in zijn Lamarckiana-familie ontstane gigasvorm heeft DE VRIES ${ }^{1}$ ) nog slechts tweemaal een gigas-vorm zien ontstaan nl. in 1898 „aus den Samen einer Pflanze von O. sublinearis, welche selbst unmittelbar aus der Lamarckiana-familie hervorgegangen war, und $1899^{\circ}$ aus einer Kreuzung von O. lata mit $O$. hirtella, einer nicht zu meinen mutirenden Familien gehörigen, in aus dem Handel bezogenen Samenzufällig gefundenen neuen Art."

„Es gelang mir” zegt hij „die ersten dieser beiden GigasPflanzen zur Blüthe zu bringen, aber die Pflanze war einjährig und das Blühen begann erst Anfang October; zu spät, dass die Samen noch reifen könnten. Ich habe die Pflanze darauf sehr genau mit der 'gleichzeitig blühenden Cultur, welche ich aus Gigas-Samen erhalten hatte, verglichen; sie stimmte mit dieser in allen wesentlichen Punkten ueberein.

Die aus $O$. lata mutirte Pflanze starb als Rosete, ohne einen Stengel zu treiben."

Van deze beide Gigas-planten sprekend, zegt Stomps in een artikel: „Die Entstehung van Oenothera gigas DE VRIEs" op p. 413: "Diese beiden Exemplare waren aber steril und brachten keinen Samen hervor." Het laatste volgt uit het eerste, maar het eerste behoeft geenszins uit het laatste te volgen, ook een niet-steriele vorm kan te gronde gaan zonder zaden voort te brengen en zooals uit bovenstaande aanhalingen van $D_{E}$ VRIEs blijkt, zegt deze volstrekt niet dat

1) Mutationstheorie Bd I p. 231. 
zijn planten steriel waren doch slechts dat zij geen zaden voortbrachten.

Wat nu den aard van DE VRIEs' Gigas betreft heeft Miss Lutz ontdekt, dat het aantal chromosomen in de somatische cellen van deze 28 bedraagt, terwijl dat van Lamarckiana (GAtes, Miss Lutz, GeERTs) 14 bedraagt. Het haploide getal van Lamarckiana, zoowel als van biennis (GATES) grandiflora (DAvis) lata, rubrinervis, laevifolia, nanella (alle GATEs) oblonga, albida en nanella (alle Miss LUTZ) bedraagt dus 7; Lamarckiana, uit welke DE VRIEs' Gigas ontstond is dus diploid, gigas tetraploid. O. gigas onderscheidt zich dus van de "soort" uit welke zij ontstond door een dubbel aantal chromosomen, wat nog niet zeggen wil dat zij, zooals STomps(Ber. D. Bot. Ges. 1912 p.) 407 zegt, een ,verdoppelte Chromosomenzahl” bezit, want die uitdrukking ,verdoppelt" houdt verband met eene het eerst door Gates (Archiv. für Zellforschung Bd. 3 Heft 4 1919) verdedigde, opvatting, dat het dubbele aantal chromosomen van $O$. gigas te danken zou zijn aan eene overlangsche splijting der chromosomen, eene opvatting waaraan zich STRasburger (Chromosomenzahl Flora Bd. 100 1910) aansloot, en waaruit Stomps 1. c. 1912 p. 408 besluit: "Hauptsache für uns ist, dass man allgemein annimmt, dass die Verdoppelung der Chromosomenzahl bei der Entstehung van $O$. gigas durch eine Längsspaltung stattgefunden hat."

Wat het tijdstip dezer veronderstelde verdubbeling aangaat, zoo hield Gates het voor waarschijnlijk, dat deze in een bevrucht nog ongedeeld ei of althans kort na de bevruchting, bij eene kerndeeling zonder daarop volgende celdeeling had plaats gevonden, eene meening die door Strasburger gedeeld werd; daarentegen heeft Stomps (Kerndeeling en Synapsis bij Spinacia oleracea L. Amsterdam 1910 p. 52-64) de meening verdedigd, dat deze verdubbeling reeds vóór de bevruchting moet plaats hebben gegrepen, en wel in beide gameten die te zamen een $O$. gigas opleveren. STomps verdedigt dus eene haploide verdubbeling tegenover de diploide verdubbeling, die door Gates en Strasburger wordt aangenomen.

Tegen de door STomps vermoedde wijze van ontstaan van $O$. gigas voerde Gates (Arch. f. Zellf. Bd 3. Heft 4. 1909 S. 544) aan „If this were the method of origin one would expect to find mutants occurring with 21 chromosomes" $\mathrm{nl}$. in die gevallen waarin een normale Lamarckiana gameet met 7 chromosomen met een "gemuteerde" met 14 chromosomen zich vereenigde. Zulke vormen waren toen 
niet bekend en dat sprak zéér voor Gates' opvatting, dat de verdubbeling der chromosomen eerst na de bevruchting heeft plaats gegrepen.

In 1911 vond echter STomps in eene Lamarckiana-cultuur inderdaad zoo'n semi-gas met 21 chromosomen en hoorde van DE VRIEs, dat deze meerdere malen dergelijke planten uit $O$. Lamarckiana had zien ontstaan.

Dit sprak nu weer zéér ten gunste van STomps opvatting, en deze meende zelfs ze daarmede bewezen te hebben, wat zeer begrijpelijk is.

Evenwel heeft STomps hiermede wel bewezen, dat het dubbele chromosomen getal reeds in de gameten van den vorm waaruit gigas ontstaat aanwezig was, maar niet dat de oorzaak van dit dubbele aantal eene haploide verdubbeling was.

$\mathrm{Er}$ is nog eene derde mogelijkheid nl. deze, dat de gameten met een dubbel aantal chromosomen eigenlijk slechts pseudo-gameten zijn, ontstaan doordat de reductie-deeling achterwege bleef. Komen dan twee zulke pseudo-gameten te zamen, dan ontstaat een tetraploide gigas-vorm, komt één zoo'n pseudo-gameet met een werkelijke gameet samen, dan ontstaat een triploide semi-gigas of Hero-vorm.

Sinds wij weten dat $O$. Lamarckiana geen Lamarckiana-gameten, maar velans en gaudens gameten vormt, is de logische consequentie van deze laatste opvatting, zooals RENNER 1) zeer terecht zegt, dat dan tetraploide gigas een (velans + gaudens) $\times($ velans + gaudens) verbinding moet zijn. Wat de triploide gigas vormen betreft, zoo kunnen deze dan òf (velans + gaudens) $\times$ gaudens òf (velans + gaudens) $\times$ velans verbindingen zijn. Op deze basis zijn dus 3

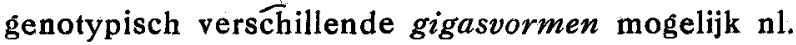

1 tetraploide $=($ velans + gaudens $) \times($ velans + gaudens $)$.

2 triploiden nl.: (velans + gaudens $) \times$ velans. en (velans + gaudens) $\times$ gaudens.

$\mathrm{Nu}$ heeft Heribert Nilsson inderdaad 3 verschillende gigasvormen, wier chromosomengetal echter niet bekend is, in zijne culturen aangetroffen die hij van elkaar als gigantea, excelsa en stricta onderscheidt. Echte gigas, gelijk aan de door DE VRIES verkregene, vond hij niet, zoodat wij niet 3 maar 4 gigas-typen hebben! Wat echter een gevolg kan zijn van de omstandigheid, dat

1) Zschr. f, ind. etc. 181917 p. 256 , 
Heribert NiLsson's Lamarckiana, zooals trouwens bij een Linneon niet anders te verwachten is (op dit punt komen wij straks uitvoerig terug) genotypisch van DE VRIEs' Lamarckiana verschilt.

Stricta en excelsa splitsen Lamarckiana af ,sind also," zegt ReNNER (l. c. p. 258) ,vielleicht triploide semigigas-Formen, und solche sind natürlich von ein und derselben Mutterpflanze als (gaudens + velans) $\times$ gaudens und als $($ gaudens + velans $) \times$ velans möglich, wobei ausserdem noch die haploiden Keimzellen mutiert sein, Mittelbildungen zwischen gaudens und velans darstellen können. Die dritte Riesenform von Heribert Nilsson, die gigantea, spaltet keine Lamarckiana ab und ist vielleicht tetraploid."

Niet alleen van Lamarckiana, maar ook van andere "soorten" zijn gigas-vormen bekend.

Bartlett (fide Stomps Biol. CB1. 361916 p. 130) kon gigasvormen met 28 chromosomen constateeren bij $O$. stenomeres en bij $O$.pratincola; gigas-vormen met 21 chromosomen kon Miss LuTZ (Biol. CBl. 32 1912) bij O. lata aantoonen, terwijl STOMPs nog 'n semigigas vorm in de $2 \mathrm{e}$ generatie van eene kruising van $O$. biennis cruciata en $O$. biennis (Biol. CBl. 321912 p. 533) aantrof en wel bij een uitgemendeld biennis-exemplaar, waarom hij deze biennis-semigigas noemt.

Verdere gigas-vormen zijn mij uit de litteratuur niet bekend, het is echter zeer wel mogelijk, dat ik er enkele over het hoofd heb gezien, de litteratuur is zoo groot geworden, dat iemand, die experimenteert, eenvoudig geen tijd meer heeft om alles na te pluizen. Een systematisch geordende uitvoerige samenvatting der Oenotheralitteratuur, bij welker vervaardiging het Sammelreferaat van E. LEHMANN in het Zschr. für Botanik X Heft 9 een uitstekende leiddraad zou kunnen geven, is een desideratum.

Algemeen meende men dus, dat waar gigas-vormen ontstaan althans een der beide gameten, waaruit deze ontstaan dubbel zooveel chromosomen heeft als de vorm uit welke die gigas-vorm ontstond, terwijl sommigen meenen, dat de gameten met het dubbele chromensomengetal, dit getal niet aan een haploide verdubbeling te danken hebben maar aan een niet plaats gegrepen reductiedeeling. dat zij dus pseudo-gameten zijn.

In geval deze opvatting juist is, zijn er dus als de Oenotheravorm, waaruit de gigas-vorm ontstaat normaliter de gameten $\mathbf{A}$ en $\mathrm{B}$ vormt, 3 verschillende gigas-typen mogelijk $\mathrm{nl}$ : 


$$
\begin{array}{cccc}
1 & \text { met de constitutie } & (\mathrm{A}+\mathrm{B}) \times(\mathrm{A}+\mathrm{B}) \\
1 & = & & (\mathrm{A}+\mathrm{B}) \times \mathrm{A} \\
1 & " & \# & (\mathrm{~A}+\mathrm{B}) \times \mathrm{B}
\end{array}
$$

Blijft echter de mogelijkheid, dat het dubbele chromosomengetal niet de oorzaak der gigas-eigenschappen is, doch slechts een bijkomende omstandigheid.

Voor die opvatting sprak eene waarneming van GeERTs, aan een exemplaar van een fertiel "Ras" van DE VRIEs van O. gigas $\times$ Lamarckiana. Daarover zegt DE VRIEs in een noot in zijn Gruppenweise Artbilding op p. 183 :

„J. M. Geerts berichtet, dass er in den vegetativen Kernen eines Individuums der $z$ weiten Generation dieser fertilen Rasse von $O$. gigas $\times$ Lamarckiana nur 14 Chromosomen gefunden hat. Siehe: Ber. d. d. bot. Ges. 1911. Bd. XXIX. S. 163. Da diese Generation der ersten aüsserlich gleich war, hat die Anfangspflanze meiner fertielen Rasse wohl auch nur 14 Chromosomen in ihren Kernen gehabt. Sie lebte aber 1907, kurze Zeit bevor die hohe Chromosomenzahl der $O$. gigas entdeckt wurde und somit sind ihre Kerne nicht untersucht worden."

Dat er een gigase of semi-gigas vorm met slechts het diploide chromosamen-getal zou bestaan is, zooals LEHMANN (Zschr. f. Botanik 10 p. 539) opmerkt, niet waarschijnlijk sinds WINKLER experimenteel gigas-vormen van Solanum-soorten verkregen heeft, „, welche offenbar auf Verdoppelung des Chromosomensatzes zurückzuführen sind."

De meest waarschijnlijke verklaring is dus, dat de gigas-vorm uit de kruising van $O$. gigas $\times$ Lamarckiana, van welke te verwachten was; dat zij 21 chromosomen zou hebben gehad en die er maar 14 bleek te hebben in het geheel geen gigas-vorm, maar een pseudo-gigas is geweest, niets dan een bijzonder krachtige modificatie, waarvoor ook de omstandigheid pleit, dat zij, in tegenstelling met andere semi-gigas-vormen, volkomen fertiel was.

Op dit denkbeeld ben ik gekomen door de ervaring met mijn biennilaeta gigas 2D6 opgedaan, van welke ik - naar haar uiterlijk vermoedde, dat $z$ ij geen tetraploide maar een triploide vorm zou zijn, terwijl tetraploidie vermoed werd van $2 \mathrm{Al}$. Onderstaande photo's geven een denkbeeld van deze plant als jonge en als volwassen, bloeiende, plant. 
Omtrent deze planten 2D6 en $2 \mathrm{Al} 4$ vinden wij in Genetica I p. 22 het volgende aangeteekend:

$2 \mathrm{Al} 4$ is gekenmerkt door:

le. de zeer forsche en breedbladige rozet.

2e. de witte kleur der bladmiddelnerven.

3e. de ongestippelde stengeltoppen.

4e. de anthocyaanvrije kelkbladen.

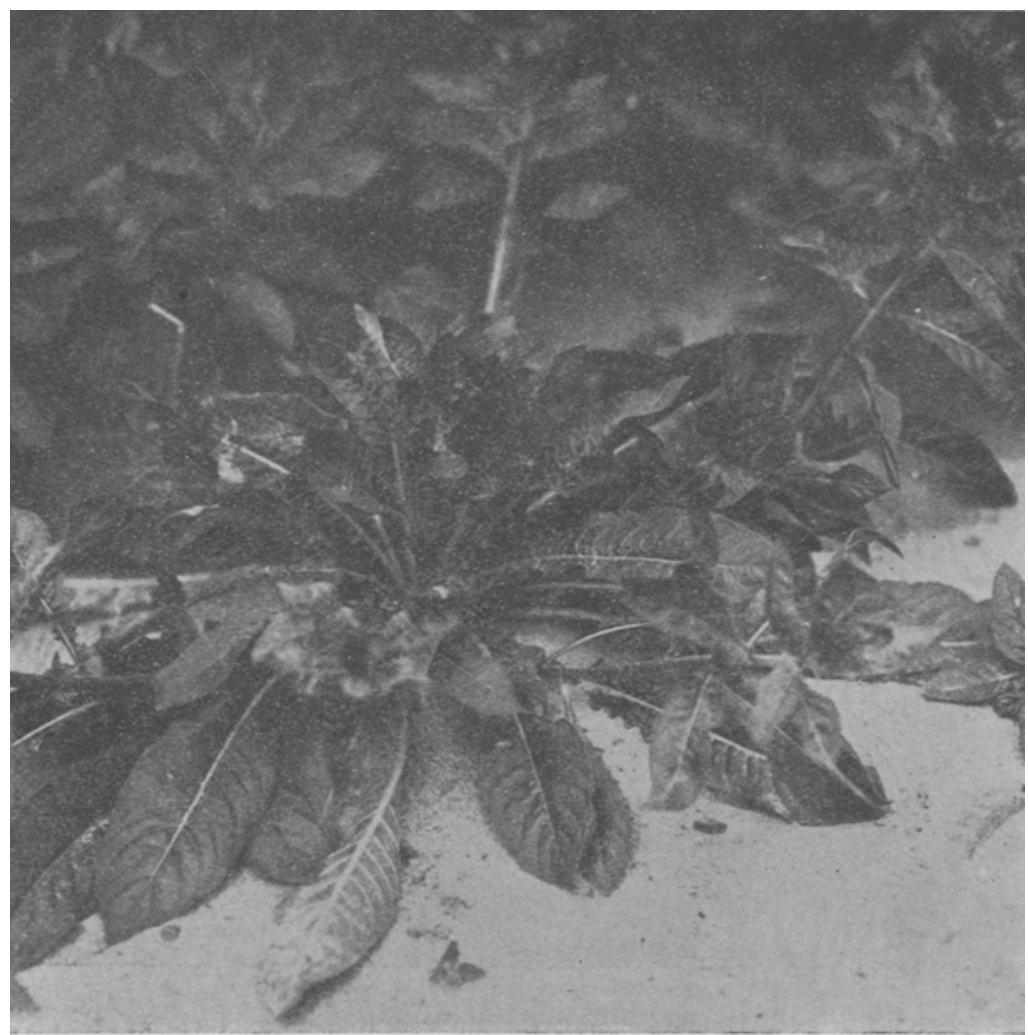

Fig. 1. O. bienni laeta, "gigas" 2D6.

5e. de bloemen, die wat hun grootte betreft, het midden houden tusschen O. fallax en O. Lamarckiana.

6e. de dikke stempellappen en de stijlen, die iets korter zijn dan de helmdraden.

7e. de afwezigheid van roode strepen op de vruchten.

8e. de aanwezigheid van uiterlijk goed pollen. 
2D6 is gekenmerkt door:

1e. de forsche en breede bladeren der rozet, ongeveer het midden boudend tusschen die van $2 \mathrm{~A} 14$ en van de gewone biennilaeta, terwijl van alle andere kenmerken wordt opgegeven: "alles geheel als bij gewone biennilaeta, hoogstens is de stijl iets korter dan bij deze en zijn de bloemen, die 's avonds vlak uitgespreid zijn iets kleiner.

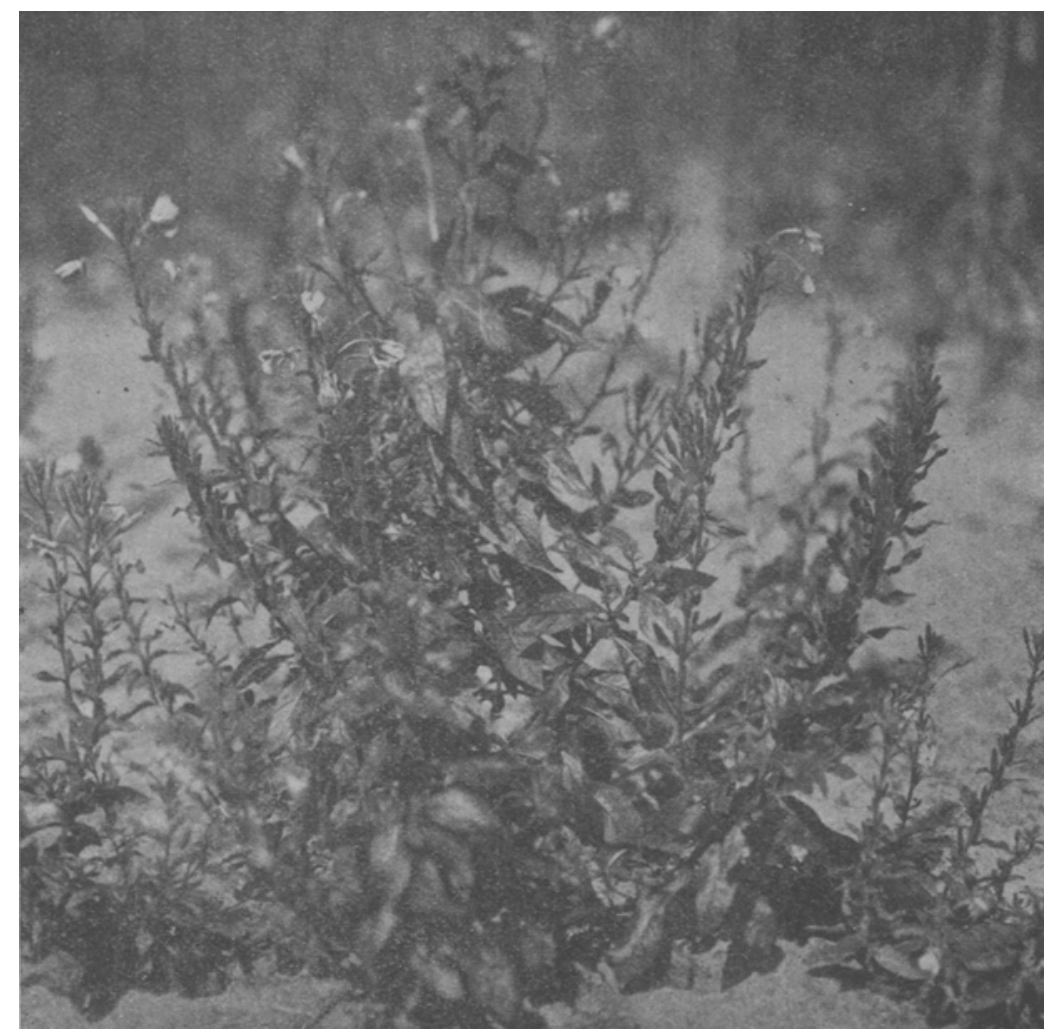

Fig. 2. Dezelfde plant als die van Fig. 1 in bloei.

Fig. 3 en 4, naar natuurgetrouwe teekeningen, geven de verschillen tusschen de rozetten dezer beide vormen aan.

In 1919 uitgezaaid gaf 2D6, zooals uit Fig. 5 blijkt uitsluitend gewone biennilaeta's Wel was het aantal niet groot (12 stuks) maar het feit, dat geen enkel exemplaar gigas-eigenschappen ver. toonde, doet toch zeer denken aan de mogelijkheid, dat deze 
2D6 slechts een luxurieerende modificatie is geweest en dat de door Geerts onderzochte gigas-vormen met 14 chromosomen ook niets anders dan zulke pseudo-gigasvormen geweest zijn.

Tegen zoodanige opvatting spreekt echter weer de omstandigheid, dat deze gigas-vorm, zooals DE VRIES uitdrukkelijk vermeldt (Gruppenweise Artbildung p. 183), constant was.

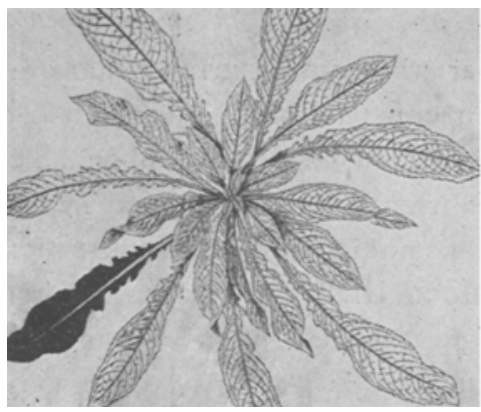

Fig. 3. Rozet van 2D6 die triploid geacht werd.

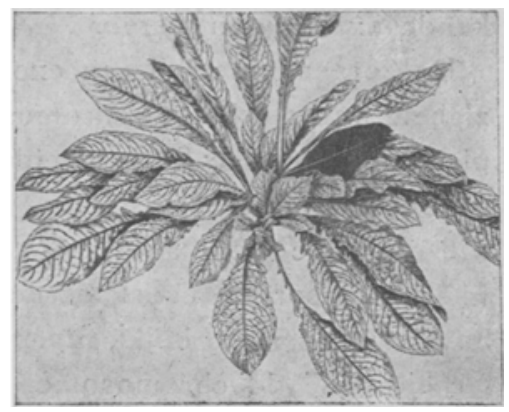

Fig. 4. Rozet van 2A14 die tetraploid geacht werd.

Zij werd verkregen door in 1905 O. gigas met Lamarckiana te kruisen. Van $1 \mathrm{ccm}$ zaden, dus van een groot aantal, ten deele

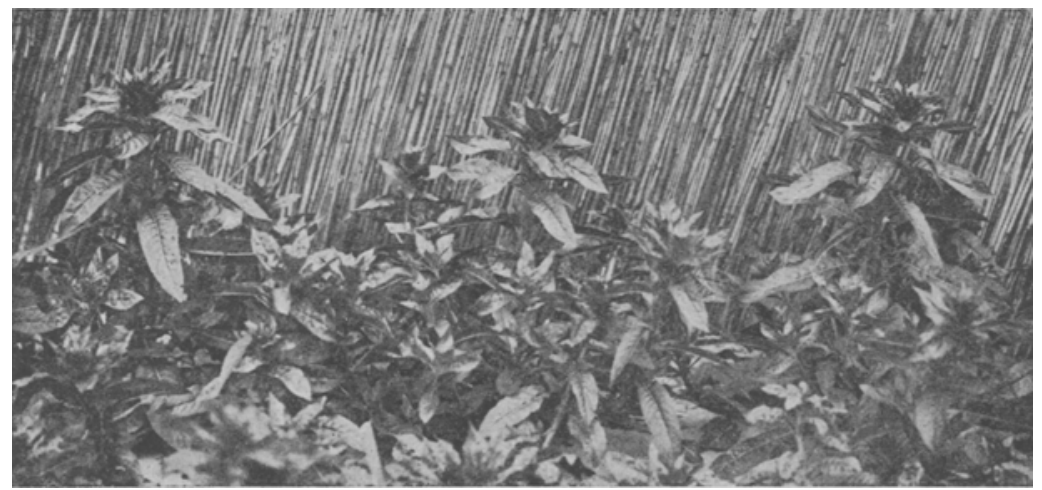

Fig. 5. Deel der cultuur no. 63. 1919, kinderen van 2D6 zelf.

in 1907, ten deele in 1908 uitgezaaid, kwamen slechts 32 resp. 30 Exemplaren op, van welke in ieder jaar 8 gebloeid hebben. „Die am frühesten blühende Pflanze von 1907 wurde mit ihrem eigenen 
Pollen rein befruchtet und gab eine reichliche Samenernte $(1 \mathrm{ccm})$ aus der ich, zegt DE VRIEs, im nächsten Jahre die zweite Generation zog." De bastaarden der eerste generatje waren alle aan elkaar gelijk ,abgesehen von einzelnen,schmalblätterigen Individuen, wie sie ja auch in reinen Culturen von $O$. gigas auf treten ${ }^{1}$ ). Drukt men dit geheel neutraal uit, dan wil dit zeggen, dat er onder de 16 Exemplaren der le generatie ,einzelne" (hoeveel ?) afwijkende exemplaren waren.

De 2e generatie (bij een exemplaar waarvan GeERTs de aanwezigheid van slechts 14 chromosomen constateerde) bestond uit 224 planten van welke 87 gebloeid en vruchten gevormd hebben. „Sie waren alle unter sich gleich und führten genau denselben Typus wie die erste Generation". Uit de omstandigheid, dat GeErts hier 14 chromosomen constateerde besloot DE VRIEs, zooals uit het bovenaangehaalde blijkt, dat ook de „Anfangspflanze” van zijn fertiel "ras" 14 chromosomen bevat. Wel is waar past deze veronderstelling zeer goed in DE VRIEs' mutatie-theorie, maar daartegen spreekt toch zeer het feit, dat de planten der eerste generatie door GeERTs onderzocht niet 14, maar 21 chromosomen bezaten.

Hieromtrent zegt Geerts Ber. D. bot. Ges. 291911 p. 163

„Oenothera gigas $\times O$. Lamarckiana ist ein konstanter intermediärer Bastard; die Pflanzen der zweiten Generation sind also denjenigen der ersten Generation ganz ähnlich, führen aber in ihren Kernen 7 Chromosomen weniger ${ }^{1}$ ).

$\mathrm{Nu}$ hebben wij gezien, dat sommige van Heribert Nilsson's reuzen vormen, die vermoedelijk 21 chromosomen hadden, Lamarckiana afsplitsen en dat mijn biennilaeta 2D6 niets dan gewone biennilaeta's gaf, zoodat in de eerste plaats gevraagd moet worden of de door GeERTs onderzochte $\mathrm{F}_{2}$ plant wel een gigas geweest is; zij zou zeer goed eene pseudo-gigas modificatie geweest kunnen zijn, zooals mijn biennilaeta gigas 2D6 er een geweest kan zijn. Ik zeg met opzet niet : geweest is, omdat het feit, dat ik alleen biennilaeta's bij het uitzaaien kreeg niet bewijst, dat er geen gigas-vormen onder de nakomelingen geweest zijn, evenmin als het feit, dat DE VRIEs geen Lamarckiana's door zijn gigas zag afsplitsen bewijst dat dit niet is geschied. Uit DE VRIEs' zaaiproeven toch blijkt duidelijk dat een groot aantal der uitgezaaide zaden

1) door mij gecursiveerd. 
geen planten heeft opgeleverd en hetzelfde was bij mijn 2D6 het geval. $\mathrm{Nu}$ is mij dit jaar gebleken hoezeer men door zoo'n omstandigheid bedrogen kan worden. Verleden jaar toch gaf een zaaisel van een aureabonte Oenothera-tak (zie later in dit artikel) bijna uitsluitend groene nakomelingen terwijl bij een hernieuwde zaaing dit jaar gebleken is, dat er vermoedelijk zeer veel aureabonten gevormd worden, maar dat deze grootendeels reeds als kiemplantjes te gronde gaan, en dat die te gronde gaande kiemplantjes zeer gemakkelijk over het hoofd worden gezien, omdat zij niet wit, doch slechts wat minder donkergroen zijn dan de plantjes, die tot gewone groene planten opgroeien.

Men ziet: het gigas-probleem is nog niet „endgültig” opgelost. Uit het tot nu toe vernomene, is echter de meest waarschijnlijke hypothese deze, dat de gigas-eigenschappen inderdaad het gevolg zijn van een dubbel chromosomen-stel, ontstaan door het achterwege blijven van de reductie-deeling bij de plant waaruit de gigas vorm ontstaat, zoodat tetraploide gigas-vormen het product zijn van twee pseudo-gameten en triploide gigas-vormen het product van één pseudo-gameet en één werkelijke gameet.

GeERTs heeft echter in zijn "Cytologische Untersuchungen einiger Bastarde van Oenothera gigas" (Ber. D. Bot. Ges. 291911 p. 160 165) op een andere mogelijkheid gewezen, nl. op deze dat een gedeelte van het chromosomenstel voldoende zou zijn om alle voor gigas characteristieke eigenschappen te veroorzaken.

Hij vond nl. dat zoowel bij $O$. gigas, als bij $O$. lata $\times$ gigas, $O$. Lamarckiana $\times$ gigas en $O$. gigas $\times$ Lamarckiana, in de aequatoriaal plaat der reductie-deeling 21 chromosomen aanwezig zijn, maar dat, terwijl in de kernen der Oenothera Lamanckiana alle chromosomen paarsgewijze gerangschikt zijn, in deze kernplaten duidelijk 7 paren en 7 afzonderlijke chromosomen aanwezig zijn. In de vegetatieve kernen is de karyokinese normaal, zoodat iedere dochterkern 21 chromosomen ontvangt, bij de reductie-deeling echter worden wel de 7 gepaarde chromosomen regelmatig over de dochterkernen verdeeld, maar gaan van de ongepaarde gewoonlijk 3 naar de eene en 4 naar de andere pool, zoodat de dochter kernen 10 of 11 chromosomen verkrijgen. Bij de tweede deeling werden ,7 deutlich gespaltene Chromosomen in die Kernplatte eingereiht und 3 kleinere, welche entweder eine mehr oder weniger tiefe Einschnü. 
rung zeigen oder sehr unregelmässig gebildet sind. In jeder Spindel lösen sich also von 7 Chromosomen die Hälften von einander und wandern nach dem Pole, während die anderen Chromosomen in der Spindel verteilt liegen oder in Stückchen zerfallen." Op deze wijze kunnen generatieve cellen met 10 en 11 chromosomen en andere met slechts 7 chromosomen ontstaan.

GEERTs, zich baseerend op zijn vondst van slechts 14 chromosomen bij een plant met gigas-habitus in de $2 \mathrm{e}$ generatie, besluit hieruit dat „wenn die Chromosomen wirklich die Träger der erblichen Eigenschaften sind, also 7 chromosomen der $O$. gigas für die Vertretung aller erblichen gigas-Eigenschaften in diesen Hybriden genüge."

Het spreekt van zelf , dat deze meening staat of valt met het feit of er werkelïk gigas-vormen met 14 chromosomen bestaan. ${ }^{1}$ )

De gigas-vorm met 14 chromosomen door GEERTs onderzocht was wellicht een pseudo-gigas, zooals mijn biennilaeta 2D6, die uitsluitend biennilaeta-nakomelingen gaferwaarschijnlijkeen geweestis.

Hoewel deze opvatting, bij den tegenwoordigen stand onzer kennis, mij de waarschijnlijkste lijkt, staat het evenwel niet vast dat zij de juiste is.

Het door Geerts opgeworpen denkbeeld, dat een gedeelte van het chromosomenstel van een bepaalden vorm voldoende is om alle dien vorm caracteriseerende eigenschappen te veroorzaken verdient zeer zeker overweging.

1) Het feit, dat GeERTs bij gigas*vormen gameten met 10 en met 11 chromosomen naast zulke met 7 chromosomen aantrof kan, in verband met het door Heribert NiLsson waargenomene afsplitsen van O. Lamarckiana door semi-gigas-vormen, ook zóó verklaard worden, dat een gameet met 7 chromosomen, parend met een andere gameet met 7 chromosomen $O$. Lamarckiana geeft, met andere woorden, dat er twee soorten van gameten met 7 chromosomen zijn nl. velans en gaudens-gameten, terwijl uit een gameet met 11 chromosomen, parend met een gameet met 10 chromosomen een semi-gigasvorm ontstaat.

Evenwel kan men ook aannemen, dat de gameten met 10 en 11 chromosomen te gronde gaan, dat deze slechts abnormaliteiten zijn, dat de Lamarckiana's, die afgesplitst worden ontstaan uit de velans- en gaudens-gameten met 7 chromosomen en dat de semi-gigas-vormen ontstaan uit gameten, die geen reductie deeling ondergingen, dus uit (gaudens + velans) gameten parend met velans. of gaudens-gameten. 
De uiterste consequentie dezer opvatting zou natuurlijk deze zijn, dat één chromosoom in staat zou zijn alle characteristieke eigenschappen van een Oenothera-,,soort" te veroorzaken.

Dit denkbeeld is, onafhankelijk van elkaar, bij mijn beide assistenten, Goedewaagen en Koolman opgekomen en de laatste heeft zijn denkbeelden hieromtrent op schrift gesteld. In dit zelfde nummer zal men zijn uiteenzettingen aantreffen, in het vervolg van dit artikel kom ik op deze terug.

(Wordt vervolgd.)

(Ingezonden: 1 April 1920.) 